Article

\title{
The Effects of the Planet-Gear Manufacturing Eccentric Errors on the Dynamic Properties for Herringbone Planetary Gears
}

\author{
Fei Ren ${ }^{1, *}$, Ansheng $\mathrm{Li}^{1, *}$, Guiqin $\mathrm{Shi}^{2, *}$, Xiaoling $\mathrm{Wu}^{3,4}$ and Ning Wang ${ }^{5}$
}

1 School of Mechanical and Electrical Engineering \& Henan Key Laboratory of Intelligent Manufacturing of Mechanical Equipment, Zhengzhou University of Light Industry, Zhengzhou 450002, China

2 School of Food and Bioengineering, Zhengzhou University of Light Industry, Zhengzhou 450002, China

3 State Key Laboratory of Mechanical Transmission, Chongqing University, Chongqing 400044, China; xlwu20@163.com

4 School of Mechanical Engineering, Zhengzhou University, Zhengzhou 450000, China

5 Underground Space Design and Research Institute, China Railway Engineering Equipment Group Co. Ltd., Zhengzhou 450016, China; ourchinabeijing208@163.com

* Correspondence: renfei2015@zzuli.edu.cn (F.R.); liansheng@zzuli.edu.cn (A.L.); 2013031@zzuli.edu.cn (G.S.)

Received: 4 January 2020; Accepted: 3 February 2020; Published: 5 February 2020

\begin{abstract}
In the presence of manufacturing errors, the dynamic properties of herringbone planetary gear train (HPGT) can be altered from the originally designed properties to have undesired behavior. In this paper, by considering the herringbone gear actual structure characteristics, manufacturing eccentric errors of members (i.e., carrier and gears) and tooth profile errors of gears, time-varying meshing stiffness, bearing deformation, and gyroscopic effect, a novel lateral-torsional-axial coupling dynamic model for the herringbone planetary gear system is formulated by using the lumped-parameter method, which is able to be employed in the dynamic feature analysis of the HPGT with an arbitrary number of planets and different types of manufacturing errors. By applying the variable-step Runge-Kutta algorithm, the dynamic response of a HPGT system is studied for cases with and without planet-gear eccentric error excitations. The dynamic contact forces of gears and bearings are analyzed for the two cases in time and frequency domains, respectively. Moreover, the effect of the planet-gear eccentricity on the vibration accelerations of the HPGT system is also discussed. The obtained results indicate that manufacturing error excitations such as the planet-gear eccentricity have a pronounced influence on the dynamic behavior of the HPGT system.
\end{abstract}

Keywords: herringbone planetary gears; dynamic model; manufacturing eccentric errors; dynamic bearing forces; dynamic mesh forces; vibration accelerations

\section{Introduction}

Owing to the characteristics of power split flow, compactness, and high torque-to-weight ratio, planetary gear train (PGT) is extensively employed in various industrial applications, such as in aerospace, automobiles, wind turbines, and nuclear power plants. In contrast to spur or helical gears, herringbone gears possess many benefits, including smoother transmission, lower axial force, and greater transmission torque. Consequently, the herringbone planetary gear system has also been used in the power train of heavy machinery such as aerospace engines, and long-wall shearers. The existence of inevitable processing errors in the manufacturing process of a drive train can significantly affect the reliability and durability of herringbone planetary gears. Nevertheless, there have been few related reports on the manufacturing error impacts on the dynamic properties of herringbone planetary gears. For the sake of achieving reliable and quiet operation, it is vital 
and necessary to formulate a dynamic model of herringbone planetary gears for the analysis of manufacturing error effects on dynamic properties.

There have been several investigations into the PGT dynamic properties. Lin and Parker constructed a spur PGT dynamic model to examine the modal characteristics [1,2]. Guo established an analytical model of spur PGTs with bearing backlash nonlinearity and tooth wedging [3]. Zhao and Ji proposed a nonlinear torsional model of multi-stage spur PGTs applied to a wind turbine gearbox for the analysis of nonlinear vibration characteristics [4]. Kahraman presented an analytical model for a stage of helical PGT for the study of its dynamic behavior [5]. Based on the lumped-parameter and finite element theories, Tatar et al. constructed a three-dimensional analytical model of helical planetary geared rotor sets by considering gyroscopic effects to investigate the dynamic behavior [6]. $\mathrm{Bu}$ incorporated journal bearings to a dynamic model of herringbone planetary gears to study their modal properties [7]. Sondkar and Kahraman investigated the free and forced vibration characteristics of double-helical planetary gears [8]. Chaari considered the eccentric and profile errors and examined the manufacturing error impacts on the spur PGT dynamic properties [9]. Xu studied the influences of pin error and stiffness in wind turbine gearbox on the PGT load distribution performance [10]. Ren et al. conducted a study of the manufacturing error effects on dynamic performance and load distribution properties for HPGT [11-14]. Zhu et al. explored the impact of meshing-frequency and run-out errors on dynamic load distribution among different planets for encased differential gear sets [15].

However, there has been no research on the impact of manufacturing errors such as the planet-gear eccentricity on the dynamic properties for herringbone planetary gears. In this paper, by considering the actual structural features of herringbone gears, a novel transverse-axial-torsional coupling dynamic analytical model for herringbone planetary gears involving manufacturing errors is formulated by applying the lumped-parameter method. The dynamic features of a HPGT system are then numerically studied, and the impacts of manufacturing errors such as the planet-gear eccentricity on the dynamic performance are examined.

\section{Components and Drive Principle}

The schematic of the components and drive principle of the herringbone planetary gear is shown in Figure 1, which are composed of a sun gear $s$, a planet-carrier $c$, a right ring gear $r 1$, a left ring gear $r 2$, and $N$ uniform planet gears $p$. Here, the sun gear connects with the high-speed input shaft, while the carrier is linked with the low-speed output shaft. The sun gear is subjected to the input torque and eventually the power is transmitted to the external load by the carrier as an output. The planets and sun adopt the herringbone gears, whereas the left and right stationary ring gears use two internal helical gears possessing opposite helical angles.

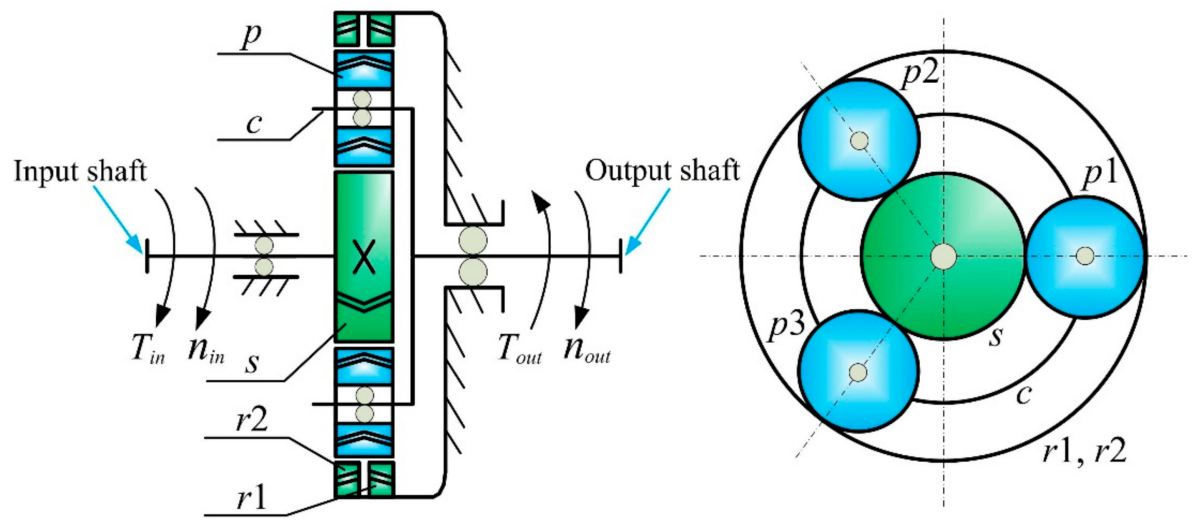

Figure 1. Structural diagram of herringbone planetary gears. 


\section{Dynamic Model and Equations of Motion}

\subsection{Dynamic Model}

Figure 2 shows the developed transverse-axial-torsional coupling dynamic model of the herringbone planetary gear set. All the gears (i.e., the sun, two rings, and planets) and the planet-carrier are considered to be rigid bodies. Bearing components are modeled by linear springs between their housings and bodies. Linear springs applied along the action line denote gear mesh interactions. The damping, gravity and friction impact are neglected, and the tilting motion is ignored. Each member possesses four degrees of freedom (DOFs), including one axial translation, two lateral translations, and one rotation. As demonstrated in Figure 2, there are three kinds of reference frames established, namely (1) the static reference frame $O X Y Z,(2)$ the dynamic reference frame $O x y z$ rotating around the coordinate origin $O$ together with the carrier, and (3) the dynamic reference frame $O_{i} x_{i} y_{i} z_{i}$ rotating with the carrier, whose origin $O_{i}$ is at the $i$ th planet-gear's center, and $x_{i-}, y_{i}$-axis are, respectively, in the radial and tangential direction.



Figure 2. Bending-torsional-axial coupling dynamic model of herringbone planetary gears taking both sides of each gear into consideration. For simplicity, only one planet-gear is exhibited and the carrier is not displayed in the figure.

Translational coordinates $x_{i}, y_{i}, z_{i}(i=c, r 1, r 2, s)$ are respectively assigned to the carrier, right ring gear, left ring gear, and sun gear. Rotational coordinates are given by $u_{i}=r_{i} \theta_{i}(i=c, r 1, r 2, s, 1,2, \ldots, N)$, where $\theta_{i}$ is the rotation; $r_{i}(i=r 1, r 2, s, 1,2, \ldots, N)$ are, respectively, the base radius for the right ring, left ring, sun and planets, and $r_{c}$ is the circle radius from the center of each planet-gear to that of the carrier. Translational coordinates $x_{j}, y_{j}, z_{j}(j=1, \mathrm{~s} \ldots, N)$ are assigned to the $j$ th planet-gear, denoting the absolute radial, tangential, and axial deflections of the $j$ th planet-gear. The vector $\left[x_{s}\right.$, $\left.y_{s}, z_{s}, u_{s}, x_{r 1}, y_{r 1}, z_{r 1}, u_{r 1}, x_{r 2}, y_{r 2}, z_{r 2}, u_{r 2}, x_{c}, y_{c}, z_{c}, u_{c}, x_{1}, y_{1}, z_{1}, u_{1}, \ldots, x_{N}, y_{N}, z_{N}, u_{N}\right]^{T}$ is selected as the generalized coordinates to create the lumped-parameter dynamic analytical model for the HPGT system. $\alpha_{t}$ denotes the transverse pressure angle. $e$ represents the static transmission error. $k$ denotes the stiffness. $\varphi_{i}=2 \pi(i-1) / N$ represents the installation position angle of the planet $i$, and $\varphi_{i}$ is assumed to be positive when anticlockwise. $\beta_{b}$ is the base helix angle. Symbols $L$ and $R$ respectively represent the left side and right side of the herringbone gears in the HPGT system. spi denotes the $i$ th external meshing pair. $r 1 p i$ and $r 2 p i$ stand for the ith right- and left-side internal meshing pairs, respectively. 


\subsection{Component Acceleration Analysis in HPGT}

To conduct the dynamic analysis, the acceleration analysis of each component for herringbone planetary gears should be first carried out. The generalized coordinates of herringbone planetary gears are established in the dynamic reference frames rotating along with the carrier. However, the accelerations of component centroids used in the dynamic analysis should be the absolute acceleration, so the absolute acceleration expressed in the dynamic coordinate systems should be derived. The relationship among the reference frames is displayed in Figure 3.

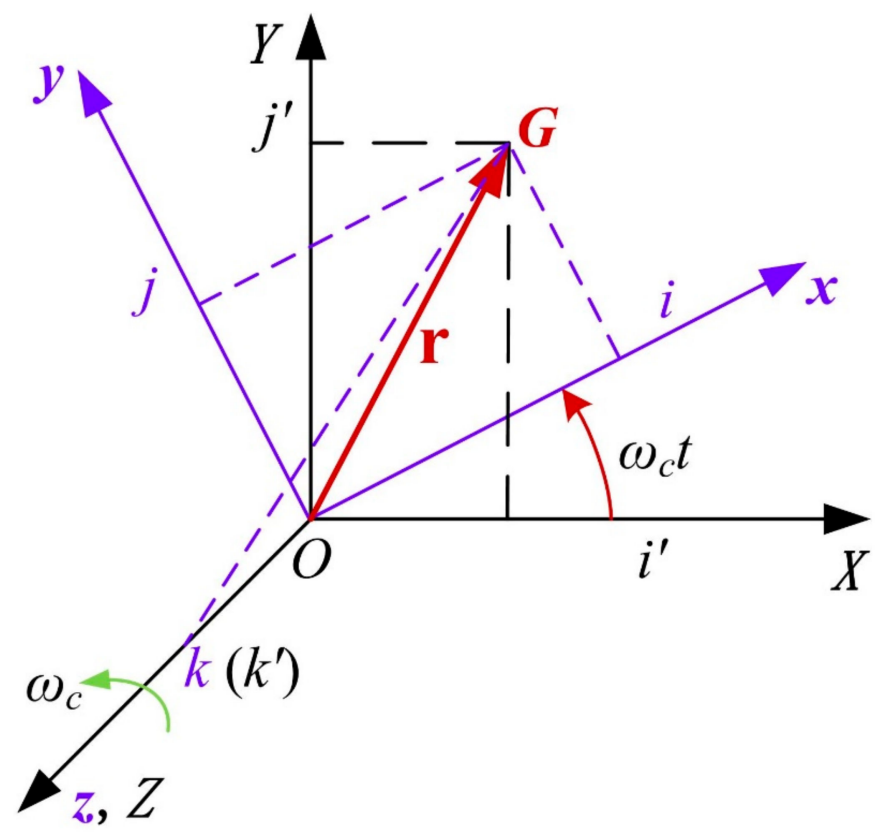

Figure 3. Coordinate transformations.

Let $G$ be the assumed centroid. Since the origin of the static reference frame $\left\{\mathbf{i}^{\prime}, \mathbf{j}^{\prime}, \mathbf{k}^{\prime}\right\}$ and the origin of the dynamic reference frame $\{\mathbf{i}, \mathbf{j}, \mathbf{k}\}$ coincide at point $\mathrm{O}$, the radius vectors of $G$ are both expressed by $\mathrm{r}$ in these two reference frames and $|\mathbf{r}|=r=\sqrt{r_{x^{\prime}}^{2}+r_{y^{\prime}}^{2}+r_{z \prime}^{2}}$. The components in the dynamic reference frame of the vector $\mathbf{r}$ are, respectively, $x \cdot \mathbf{i}, y \cdot \mathbf{j}$ and $z \cdot \mathbf{k}$, and those in the static reference frame are, respectively, $X \cdot \mathbf{i}^{\prime}, Y \cdot \mathbf{j}^{\prime}$ and $Z \cdot \mathbf{k}^{\prime}$. From Figure 3 , the radius vector can be obtained as

$$
\begin{aligned}
& \mathbf{r}=\left\{x \cdot \cos \omega_{c} t-y \cdot \sin \omega_{c} t, y \cdot \cos \omega_{c} t+x \cdot \sin \omega_{c} t, z\right\}^{T} \cdot\left\{\mathbf{i}, \mathbf{j} \mathbf{j}^{\prime}, \mathbf{k} \mathbf{\prime}\right\}^{T} \\
& =\left\{r_{x \prime}, r_{y^{\prime}}, r_{z \prime}\right\}^{T} \cdot\left\{\mathbf{i} \prime \mathbf{j}^{\prime}, \mathbf{k} \mathbf{k}^{\prime}\right\}^{T}
\end{aligned}
$$

The absolute acceleration of $G$ can be written as

$$
\mathbf{a} \prime=\left\{a_{x \prime}, a_{y^{\prime}}, a_{z \prime}\right\}^{T} \cdot\left\{\mathbf{i} \prime, \mathbf{j}^{\prime}, \mathbf{k} \prime\right\}^{T}=\left\{\ddot{r}_{x \prime}, \ddot{r}_{y \prime}, \ddot{r}_{z \prime}\right\}^{T} \cdot\left\{\mathbf{i} \prime, \mathbf{j}, \mathbf{k}^{\prime}\right\}^{T}
$$

The absolute acceleration of $G$ in the dynamic reference frame can be derived as

$$
\begin{aligned}
& \mathbf{a}=\left\{a_{x \prime} \cdot \cos \omega_{c} t+a_{y \prime} \cdot \sin \omega_{c} t, a_{y \prime} \cdot \cos \omega_{c} t-a_{x \prime} \cdot \sin \omega_{c} t, a_{z \prime}\right\}^{T} \cdot\{\mathbf{i}, \mathbf{j}, \mathbf{k}\}^{T} \\
& =\left\{\ddot{x}-2 \omega_{c} \dot{y}-\omega_{c}^{2} x, \ddot{y}+2 \omega_{c} \dot{x}-\omega_{c}^{2} y, \ddot{z}\right\}^{T} \cdot\{\mathbf{i}, \mathbf{j}, \mathbf{k}\}^{T}
\end{aligned}
$$

where $\omega_{c}$ means the angular velocity of the carrier. $2 \omega_{c} \dot{y}$ and $2 \omega_{c} \dot{x}$ represent the Coriolis accelerations of G. $\omega_{c}^{2} x$ and $\omega_{c}^{2} y$ denote the centripetal accelerations. 


\subsection{Component Equivalent Displacements in HPGT}

Figures 4-6 respectively show the dynamic models of the external (sun-planet $i$ ) and internal (carrier-planet $i$ ) mesh pair, and carrier-planet $i$ pair. In the derivation of the dynamic equations of the entire HPGT system, the relative displacements between the components in HPGT need to be obtained first. According to the motion and deformation relationships between components as shown in Figures 4-6, the relative displacements can be deduced [16-21].

(1) The equivalent deformation $\Theta_{s p i}^{L}$ of the $i$ th external mesh on the left side is written as

$$
\begin{aligned}
\Theta_{s p i}^{L} & =\left[\left(-x_{s} \sin \varphi_{s i}+y_{s} \cos \varphi_{s i}+u_{s}\right)-\left(x_{i} \sin \alpha_{t}+y_{i} \cos \alpha_{t}-u_{i}\right)\right] \cdot \cos \beta_{b} \\
& -\left(z_{i}-z_{s}\right) \cdot \sin \beta_{b}+e_{s p i}^{L}(t)
\end{aligned}
$$

(2) The equivalent deformation $\Theta_{s p i}^{R}$ of the $i$ th external mesh on the right side is expressed as

$$
\begin{aligned}
\Theta_{s p i}^{R} & =\left[\left(-x_{s} \sin \varphi_{s i}+y_{s} \cos \varphi_{s i}+u_{s}\right)-\left(x_{i} \sin \alpha_{t}+y_{i} \cos \alpha_{t}-u_{i}\right)\right] \cdot \cos \beta_{b} \\
& -\left(z_{s}-z_{i}\right) \cdot \sin \beta_{b}+e_{s p i}^{R}(t)
\end{aligned}
$$

(3) The equivalent deformation $\Theta_{r 2 p i}^{L}$ of the ith left-side internal mesh is given by

$$
\begin{aligned}
\Theta_{r 2 p i}^{L} & =\left[\left(-x_{r 2} \sin \varphi_{r i}+y_{r 2} \cos \varphi_{r i}+u_{r 2}\right)-\left(-x_{i} \sin \alpha_{t}+y_{i} \cos \alpha_{t}+u_{i}\right)\right] \cdot \cos \beta_{b} \\
& +\left(z_{i}-z_{r 2}\right) \cdot \sin \beta_{b}+e_{r 2 p i}^{L}(t)
\end{aligned}
$$

(4) The equivalent deformation $\Theta_{r 1 p i}^{R}$ of the ith right-side internal mesh is written as

$$
\begin{aligned}
\Theta_{r 1 p i}^{R} & =\left[\left(-x_{r 1} \sin \varphi_{r i}+y_{r 1} \cos \varphi_{r i}+u_{r 1}\right)-\left(-x_{i} \sin \alpha_{t}+y_{i} \cos \alpha_{t}+u_{i}\right)\right] \cdot \cos \beta_{b} \\
& +\left(-z_{i}+z_{r 1}\right) \cdot \sin \beta_{b}+e_{r 1 p i}^{R}(t)
\end{aligned}
$$

(5) The radial relative deflection $\Theta_{x c p i}$ between the $i$ th planet and the carrier is determined by

$$
\Theta_{x c p i}=-x_{i}+y_{c} \cdot \sin \varphi_{i}+x_{c} \cdot \cos \varphi_{i}
$$

(6) The tangential relative deflection $\Theta_{y c p i}$ between the $i$ th planet and the carrier is expressed as

$$
\Theta_{y c p i}=-y_{i}+y_{c} \cdot \cos \varphi_{i}-x_{c} \cdot \sin \varphi_{i}+u_{c}
$$

(7) The axial relative deflection $\Theta_{z c p i}$ between the $i$ th planet and the carrier is given by

$$
\Theta_{z c p i}=-z_{c}+z_{i}
$$




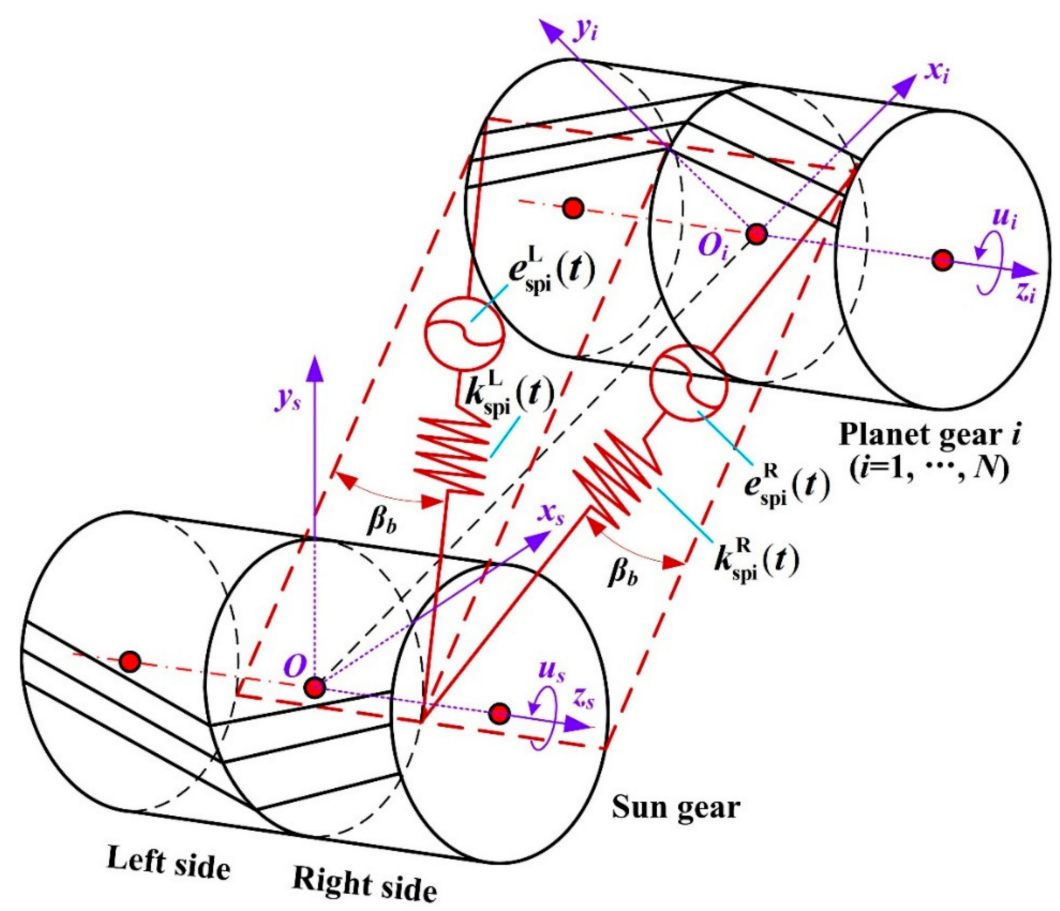

Figure 4. Dynamic model of the $i$ th herringbone planet-sun gear pair.



Figure 5. Dynamic model of the $i$ th herringbone planet-ring gear pair. 


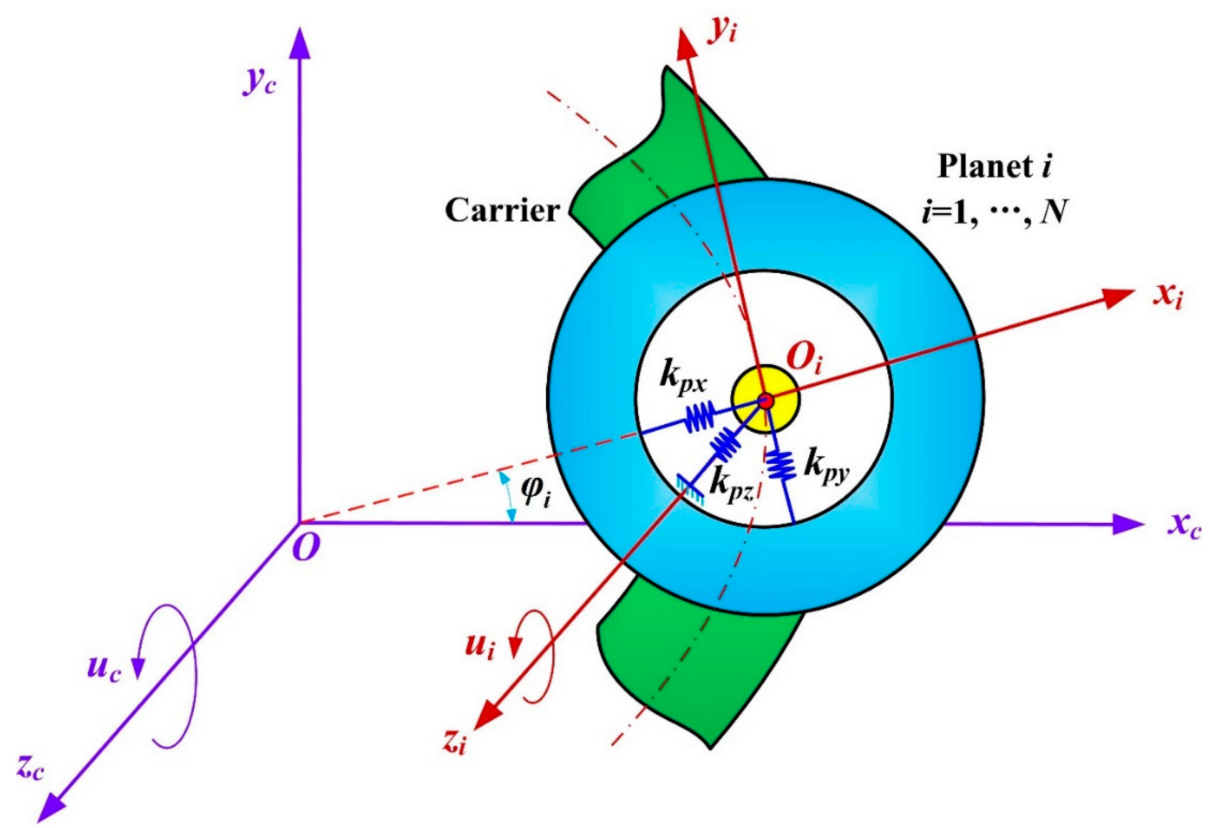

Figure 6. Dynamic model of the $i$ th herringbone planet-carrier pair.

\subsection{Equations of Motion}

Based on the dynamic models of each mesh pair as displayed in Figures 4-6, Newton's Second Law of Motion in non-inertial coordinate frames [2] is employed to acquire the equations of motion for herringbone planetary gears. The carrier's motion equations can be given by

$$
\left\{\begin{array}{l}
m_{c}\left(\ddot{x}_{c}-2 \omega_{c} \dot{y}_{c}-\omega_{c}^{2} x_{c}\right)=-\sum_{i=1}^{N} k_{p}\left(\Theta_{x c p i} \cdot \cos \varphi_{i}-\Theta_{y c p i} \cdot \sin \varphi_{i}\right)-k_{c} \cdot x_{c} \\
m_{c}\left(\ddot{y}_{c}+2 \omega_{c} \dot{x}_{c}-\omega_{c}^{2} y_{c}\right)=-\sum_{i=1}^{N} k_{p}\left(\Theta_{x c p i} \cdot \sin \varphi_{i}+\Theta_{y c p i} \cdot \cos \varphi_{i}\right)-k_{c} \cdot y_{c} \\
m_{c} \ddot{z}_{c}=\sum_{i=1}^{N} k_{p z} \Theta_{z c p i}-k_{c z} \cdot z_{c} \\
\frac{J_{c}}{r_{c}^{2}} \ddot{u}_{c}=-\sum_{i=1}^{N} k_{p} \Theta_{y c p i}-k_{c t} \cdot u_{c}-\frac{T_{c}}{r_{c}}
\end{array}\right.
$$

In a similar manner, the equations of motion of the other components for herringbone planetary gears can be derived.

The right ring gear's motion equations are represented by

$$
\left\{\begin{array}{l}
m_{r}\left(\ddot{x}_{r 1}-2 \omega_{c} \dot{y}_{r 1}-\omega_{c}^{2} x_{r 1}\right)=\sum_{i=1}^{N} k_{r 1 p i}^{R}\left(\Theta_{r 1 p i}^{R} \cdot \cos \beta_{b}\right) \cdot \sin \varphi_{r i}-k_{r} \cdot x_{r 1} \\
m_{r}\left(\ddot{y}_{r 1}+2 \omega_{c} \dot{x}_{r 1}-\omega_{c}^{2} y_{r 1}\right)=-\sum_{i=1}^{N} k_{r 1 p i}^{R}\left(\Theta_{r 1 p i}^{R} \cdot \cos \beta_{b}\right) \cdot \cos \varphi_{r i}-k_{r} \cdot y_{r 1} \\
m_{r} \ddot{z}_{r 1}=\sum_{i=1}^{N} k_{r 1 p i}^{R}\left(\Theta_{r 1 p i}^{R} \cdot \sin \beta_{b}\right)-k_{r} \cdot z_{r 1} \\
\frac{I_{r}}{r_{r}} \ddot{z}_{r 1}=-\sum_{i=1}^{N} k_{r 1 p i}^{R}\left(\Theta_{r 1 p i}^{R} \cdot \cos \beta_{b}\right)-k_{r 1 t} \cdot u_{r 1}
\end{array}\right.
$$


The left ring gear's motion equations can be expressed as

$$
\left\{\begin{array}{l}
m_{r}\left(\ddot{x}_{r 2}-2 \omega_{c} \dot{y}_{r 2}-\omega_{c}^{2} x_{r 2}\right)=\sum_{i=1}^{N} k_{r 2 p i}^{L}\left(\Theta_{r 2 p i}^{L} \cdot \cos \beta_{b}\right) \sin \varphi_{r i}-k_{r} \cdot x_{r 2} \\
m_{r}\left(\ddot{y}_{r 2}+2 \omega_{c} \dot{x}_{r 2}-\omega_{c}^{2} y_{r 2}\right)=-\sum_{i=1}^{N} k_{r 2 p i}^{L}\left(\Theta_{r 2 p i}^{L} \cdot \cos \beta_{b}\right) \cos \varphi_{r i}-k_{r} \cdot y_{r 2} \\
m_{r} \ddot{z}_{r 2}=-\sum_{i=1}^{N} k_{r 2 p i}^{\mathrm{L}}\left(\Theta_{r 2 p i}^{\mathrm{L}} \cdot \sin \beta_{b}\right)-k_{r} \cdot z_{r 2} \\
\frac{J_{r}}{r_{r}{ }_{2}} \ddot{u}_{r 2}=-\sum_{i=1}^{N} k_{r 2 p i}^{\mathrm{L}}\left(\Theta_{r 2 p i}^{L} \cdot \cos \beta_{b}\right)-k_{r 2 t} \cdot u_{r 2}
\end{array}\right.
$$

The sun gear's motion equations are given by

$$
\left\{\begin{array}{l}
m_{s}\left(\ddot{x}_{s}-2 \omega_{c} \dot{y}_{s}-\omega_{c}^{2} x_{s}\right)=\sum_{i=1}^{N}\left(k_{s p i}^{R} \cdot \Theta_{s p i}^{R}+k_{s p i}^{L} \cdot \Theta_{s p i}^{L}\right) \cdot \cos \beta_{b} \cdot \sin \varphi_{s i}-k_{s} \cdot x_{s} \\
m_{s}\left(\ddot{y}_{s}+2 \omega_{c} \dot{x}_{s}-\omega_{c}^{2} y_{s}\right)=-\sum_{i=1}^{N}\left(k_{s p i}^{R} \cdot \Theta_{s p i}^{R}+k_{s p i}^{L} \cdot \Theta_{s p i}^{L}\right) \cdot \cos \beta_{b} \cdot \cos \varphi_{s i}-k_{s} \cdot y_{s} \\
m_{s} \ddot{z}_{s}=\sum_{i=1}^{N}\left(k_{s p i}^{L} \cdot \sin \beta_{b} \cdot \Theta_{s p i}^{L}\right)-\sum_{i=1}^{N}\left(k_{s p i}^{R} \cdot \sin \beta_{b} \cdot \Theta_{s p i}^{R}\right)-k_{s z} \cdot z_{s} \\
\frac{J_{s}}{r_{s}{ }^{2}} \ddot{u}_{s}=-\sum_{i=1}^{N}\left(k_{s p i}^{R} \cdot \Theta_{s p i}^{R} \cdot \cos \beta_{b}+k_{s p i}^{L} \cdot \Theta_{s p i}^{L} \cdot \cos \beta_{b}\right)-k_{s t} \cdot u_{s}+\frac{T_{s}}{r_{s}}
\end{array}\right.
$$

The ith planet-gear's motion equations can be derived as

$$
\left\{\begin{array}{c}
m_{p}\left(\ddot{x}_{i}-2 \omega_{c} \dot{y}_{i}-\omega_{c}^{2} x_{i}\right)=\left(k_{s p i}^{R} \cdot \Theta_{s p i}^{R}+k_{s p i}^{L} \cdot \Theta_{s p i}^{L}\right) \cdot \cos \beta_{b} \cdot \sin \alpha_{t} \\
-\left(k_{r 1 p i}^{R} \cdot \Theta_{r 1 p i}^{R}+k_{r 2 p i}^{L} \cdot \Theta_{r 2 p i}^{L}\right) \cdot \cos \beta_{b} \cdot \sin \alpha_{t}+k_{p} \cdot \Theta_{x c p i} \\
m_{p}\left(\ddot{y}_{i}+2 \omega_{c} \dot{x}_{i}-\omega_{c}^{2} y_{i}\right)=\left(k_{s p i}^{R} \cdot \Theta_{s p i}^{R}+k_{s p i}^{L} \cdot \Theta_{s p i}^{L}\right) \cdot \cos \beta_{b} \cos \alpha_{t} \\
+\left(k_{r 1 p i}^{R} \cdot \Theta_{r 1 p i}^{R}+k_{r 2 p i}^{L} \cdot \Theta_{r 2 p i}^{L}\right) \cdot \cos \beta_{b} \cdot \cos \alpha_{t}+k_{p} \cdot \Theta_{y c p i} \\
m_{p} \ddot{z}_{i}=k_{s p i}^{R} \cdot \sin \beta_{b} \cdot \Theta_{s p i}^{R}-k_{s p i}^{L} \cdot \sin \beta_{b} \cdot \Theta_{s p i}^{L}-k_{r 1 p i}^{R} \Theta_{r 1 p i}^{R} \cdot \sin \beta_{b} \\
+k_{r 2 p i}^{L} \Theta_{r 2 p i}^{L} \cdot \sin \beta_{b}-k_{p z} \cdot \Theta_{z c p i} \\
\frac{J_{p}}{r_{p}{ }^{2}} \ddot{u}_{i}=-\left(k_{s p i}^{R} \Theta_{s p i}^{R}+k_{s p i}^{L} \Theta_{s p i}^{L}\right) \cdot \cos \beta_{b}+\left(k_{r 1 p i}^{R} \Theta_{r 1 p i}^{R}+k_{r 2 p i}^{L} \Theta_{r 2 p i}^{L}\right) \cdot \cos \beta_{b}
\end{array}\right.
$$

where $m_{g}$ and $J_{g}(g=s, p, c, r)$ represent the mass and rotational inertia of member $g$, respectively. $N$ refers to the plane number. $k_{n}$ and $k_{n z}$ are the $x$-or $y$-direction and $z$-direction support stiffness of member $n(n=s, p, c, r 1, r 2)$, respectively. $k_{n t}(n=r 1, r 2)$ respectively means the torsional support stiffness of the right and left ring gear. $k_{s p i}^{L}, k_{s p i}^{R}, k_{r 2 p i}^{L}$ and $k_{r 1 p i}^{R}$ stand for the meshing stiffness of the $i$ th external and internal meshing pairs on the left and right sides, respectively.

The motion equations of the dynamic model exhibited in Figure 2 can be rewritten in matrix form as

$$
[\mathbf{M}] \cdot \ddot{\mathbf{U}}(\mathbf{t})+\boldsymbol{\omega}_{\mathbf{c}} \cdot[\mathbf{G}] \cdot \dot{\mathbf{U}}(\mathbf{t})+\left(\left[\mathbf{K}_{\mathbf{b}}\right]+\left[\mathbf{K}_{\mathbf{m}}(\mathbf{t})\right]-\boldsymbol{\omega}_{\mathbf{c}}^{2} \cdot\left[\mathbf{K}_{\Omega}\right]\right) \cdot \mathbf{U}(\mathbf{t})=\mathbf{F}(\mathbf{t})+\mathbf{T}
$$

where $\mathbf{U}(\mathbf{t}), \dot{\mathbf{U}}(\mathbf{t})$ and $\ddot{\mathbf{U}}(\mathbf{t})$ respectively represent the HPGT generalized displacement, velocity and acceleration vectors and $\mathbf{U}(\mathbf{t})=\left\{x_{s}, y_{s}, z_{s}, u_{s}, x_{r 1}, y_{r 1}, z_{r 1}, u_{r 1}, x_{r 2}, y_{r 2}, z_{r 2}, u_{r 2}, x_{c}, y_{c}, z_{c}, u_{c}, x_{1}, y_{1}, z_{1}, u_{1}, \ldots\right.$, $\left.x_{N}, y_{N}, z_{N}, u_{N}\right\}^{T}$. $[\mathbf{M}]$ refers to the HPGT generalized mass matrix, $\left[\mathbf{K}_{\mathbf{b}}\right]$ is the bearing stiffness matrix. $\left[\mathbf{K}_{\mathbf{m}}(\mathbf{t})\right]$ indicates the time-varying meshing stiffness matrix where $\left[\mathbf{K}_{\mathbf{m}}(\mathbf{t})\right]=\left[\mathbf{K}_{\mathbf{m}}^{\mathbf{L}}(\mathbf{t})\right]+\left[\mathbf{K}_{\mathbf{m}}^{\mathbf{R}}(\mathbf{t})\right] \cdot[\mathbf{G}]$ represents the gyroscopic matrix. $\left[\mathbf{K}_{\Omega}\right]$ is the centripetal stiffness matrix. $\mathbf{F}(\mathbf{t})$ denotes the HPGT load vector including the internal exciting force vector which arises from the static transmission error due to elastic deflections and manufacturing errors. $T$ is the HPGT external exciting force vector and $\mathbf{T}=\left\{0,0,0, T_{s} / r_{s}, 0,0,0,0,0,0,0,0,0,0,0,-T_{c} / r_{c}, 0,0,0,0, \ldots, 0,0,0,0\right\}^{T}$, where $T_{g}(g=s, c)$ is the external torques applied on the component $\mathrm{g}$. 


\section{Internal Excitations}

\subsection{Error Excitation}

This paper considers the manufacturing eccentric errors of each member (i.e., carrier and each gear) as well as tooth profile errors of each gear. These manufacturing errors are projected to the contact lines of the left-side and right-side meshing pairs of the HPGT system, respectively, and finally the cumulative meshing error gained by the superposition of eccentric and tooth profile error of components at the left- and right-side action lines can be written as [11,12].

$$
\left\{\begin{aligned}
& e_{s p i}^{L}=-E_{p i} \cdot \sin \left(\left(\omega_{p}-\omega_{c}\right) \cdot t+\beta_{p i}+\alpha_{t}\right)-E_{s} \cdot \sin \left(\left(\omega_{s}-\omega_{c}\right) \cdot t+\beta_{s}+\alpha_{t}-\varphi_{i}\right) \\
&+E_{c} \cdot \sin \left(\beta_{c}-\varphi_{i}\right) \cdot \cos \alpha_{t}+E_{s p i} \cdot \sin \left(\omega_{m}\left(t+\gamma_{s i} \cdot T_{m}\right)\right) \\
& e_{r 2 p i}^{L}=+E_{p i} \cdot \sin \left(\left(\omega_{p}-\omega_{c}\right) \cdot t+\beta_{p i}-\alpha_{t}\right)+E_{r 2}^{L} \cdot \sin \left(-\omega_{c} \cdot t+\beta_{r 2}-\alpha_{t}-\varphi_{i}\right) \\
&-E_{c} \cdot \sin \left(\beta_{c}-\varphi_{i}\right) \cdot \cos \alpha_{t}+E_{r 2 p i}^{L} \cdot \sin \left(\omega_{m}\left(t+\left(\gamma_{s i}+\gamma_{s r}\right) \cdot T_{m}\right)\right) \\
& e_{s p i}^{R}=-E_{p i} \cdot \sin \left(\left(\omega_{p}-\omega_{c}\right) \cdot t+\beta_{p i}+\alpha_{t}\right)-E_{s} \cdot \sin \left(\left(\omega_{s}-\omega_{c}\right) \cdot t+\beta_{s}+\alpha_{t}-\varphi_{i}\right) \\
&+E_{c} \cdot \sin \left(\beta_{c}-\varphi_{i}\right) \cdot \cos \alpha_{t}+E_{s p i} \cdot \sin \left(\omega_{m} \cdot t+z_{s} \cdot \varphi_{i}\right) \\
& e_{r 1 p i}^{R} \quad+E_{p i} \cdot \sin \left(\left(\omega_{p}-\omega_{c}\right) \cdot t+\beta_{p i}-\alpha_{t}\right)+E_{r 1}^{R} \cdot \sin \left(-\omega_{c} \cdot t+\beta_{r 1}-\alpha_{t}-\varphi_{i}\right) \\
&-E_{c} \cdot \sin \left(\beta_{c}-\varphi_{i}\right) \cdot \cos \alpha_{t}+E_{r 1 p i}^{R} \cdot \sin \left(\omega_{m} \cdot\left(t+\left(\gamma_{r i}+\gamma_{s r}\right) \cdot T_{m}\right)\right) \\
& i=1,2, \cdots, N
\end{aligned}\right.
$$

where $e_{s p i}^{L}, e_{s p i}^{R}, e_{r 2 p i}^{L}$ and $e_{r 1 p i}^{R}$ represent the cumulative meshing errors for the $i$ th left- and right-side external and internal meshing pairs, respectively; $E_{s}, E_{p i}, E_{c}, E_{r 2}^{L}$, and $E_{r 1}^{R}$ denote the amplitudes of eccentric errors of members; $\beta_{s}, \beta_{p i}, \beta_{c}, \beta_{r 2}$, and $\beta_{r 1}$ are the eccentric error initial phases of members; $E_{s p i}, E_{r 2 p i}^{L}$ and $E_{r 1 p i}^{R}$ are the amplitudes of profile errors for each gear pair; $\omega_{g}(g=p, s, c)$ is the angle velocity of member $g ; t$ is time. $\omega_{m}$ is the system meshing angular frequency, $T_{\mathrm{m}}$ is the system meshing period.

\subsection{Time-Varying Meshing Stiffness Excitation}

For a HPGT system, based on the mesh stiffness formula of helical gears, the time-varying meshing stiffness $k_{r 2 p i}^{L}(t), k_{r 1 p i}^{R}(t), k_{s p i}^{L}(t), k_{s p i}^{R}(t)$ for the $i$ th left- and right-side internal and external meshing pairs of the system can be denoted as the first-order Fourier series form as described in Equation (18), respectively $[11,12,22]$.

$$
\left\{\begin{array}{l}
k_{s p i}^{L}(t)=\bar{k}_{s p i}^{L}+a_{s p i}^{L} \cdot \cos \left(\omega_{m} \cdot t\right)+b_{s p i}^{L} \cdot \sin \left(\omega_{m} \cdot t\right) \\
k_{s p i}^{R}(t)=\bar{k}_{s p i}^{R}+a_{s p i}^{L} \cdot \cos \left(\omega_{m} \cdot t\right)+b_{s p i}^{L} \cdot \sin \left(\omega_{m} \cdot t\right) \\
k_{r 2 p i}^{L}(t)=\bar{k}_{r 2 p i}^{L}+a_{r 2 p i}^{L} \cdot \cos \left(\omega_{m} \cdot t\right)+b_{r 2 p i}^{L} \cdot \sin \left(\omega_{m} \cdot t\right) \\
k_{r 1 p i}^{R}(t)=\bar{k}_{r 1 p i}^{R}+a_{r 2 p i}^{L} \cdot \cos \left(\omega_{m} \cdot t\right)+b_{r 2 p i}^{L} \cdot \sin \left(\omega_{m} \cdot t\right)
\end{array}\right.
$$

where $a_{s p i}^{L}, b_{s p i}^{L}, a_{r 2 p i^{\prime}}^{L}$ and $b_{r 2 p i}^{L}$ all denote the first-order Fourier coefficients, the notation $\bar{k}$ represents the average meshing stiffness. Furthermore, this paper considers the relationships of planet meshing phases, which are involved in the Fourier coefficients $a_{s p i^{\prime}}^{L}, b_{s p i^{\prime}}^{L} a_{r 2 p i}^{L}, b_{r 2 p i}^{L}$

\section{Numerical Calculation Approach}

Since the numerical integration method is widely used, which is suitable for solving any type of nonlinear differential equations, and in engineering practice, the differential equations of gear system dynamics are generally difficult to obtain accurate analytical solutions, the numerical methods have been widely applied in solving the dynamic equations of complex gear systems, where the Runge-Kutta method is the main numerical integration method. 
In the present paper, the system response is solved by using the variable-step Runge-Kutta algorithm [11,12]. To apply Runge-Kutta method to solve Equation (16), first, the descending order processing of second order differential equations is needed to transform the governing Equation (16) into a state equation of first derivative form. Thus, Equation (16) can be rewritten as

$$
\ddot{\mathrm{U}}(\mathrm{t})=[\mathbf{M}]^{-1} \cdot\left(\mathrm{F}(\mathrm{t})+\mathbf{T}-\omega_{c} \cdot[\mathbf{G}] \cdot \dot{\mathrm{U}}(\mathrm{t})-\left(\left[\mathbf{K}_{b}\right]+\left[\mathbf{K}_{m}(\mathrm{t})\right]-\omega_{\mathrm{c}}^{2} \cdot\left[\mathbf{K}_{\Omega}\right]\right) \cdot \mathbf{U}(\mathrm{t})\right)
$$

Introducing the state vector

$$
y=\left\{\begin{array}{c}
\dot{U}(t) \\
\mathrm{U}(\mathrm{t})
\end{array}\right\}
$$

Equation (19) can be written as a matrix form of first-order ordinary differential equations

$$
\dot{y}=\left[\begin{array}{cc}
-\omega_{c} \cdot[\mathbf{M}]^{-1} \cdot[\mathbf{G}] & -[\mathbf{M}]^{-1} \cdot\left(\left[\mathbf{K}_{b}\right]+\left[\mathbf{K}_{m}(t)\right]-\omega_{c}^{2} \cdot\left[\mathbf{K}_{\Omega}\right]\right) \\
\mathbf{I} & 0
\end{array}\right] \cdot y+\left[\begin{array}{c}
{[\mathbf{M}]^{-1} \cdot(\mathbf{F}(\mathbf{t})+\mathbf{T})} \\
0
\end{array}\right]
$$

while calculating, based on the above Equation (21), the ODE solver in MATLAB is used to solve the system equation.

\section{Numerical Simulations}

The parameters of a herringbone planetary gear with both stationary rings and three equally spaced planets shown in Figure 1 are given in Tables 1 and 2. The variable-step Runge-Kutta method described in Section 5 is employed for solving the system Equation (16). The dynamic responses such as the vibration accelerations of the components of the HPGT system are compared for two cases where the planet-gear eccentric error excitations are present and absent. Furthermore, the dynamic contact forces of gear and bearing for the HPGT system are also compared between the results with and without planet-gear eccentric error excitations in the time domain and frequency domain, respectively.

Table 1. Parameters of the HPGT system.

\begin{tabular}{|c|c|c|c|c|c|}
\hline Item $/\left(N \cdot m^{-1}\right)$ & Left Ring & Right Ring & Sun & Planet & Carrier \\
\hline$x$-direction & $1 \times 10^{10}$ & $1 \times 10^{10}$ & $1 \times 10^{9}$ & $1 \times 10^{9}$ & $1 \times 10^{9}$ \\
\hline$y$-direction & $1 \times 10^{10}$ & $1 \times 10^{10}$ & $1 \times 10^{9}$ & $1 \times 10^{9}$ & $1 \times 10^{9}$ \\
\hline$z$-direction & $1 \times 10^{10}$ & $1 \times 10^{10}$ & $1 \times 10^{9}$ & $1 \times 10^{9}$ & $1 \times 10^{9}$ \\
\hline$u$-direction & $1 \times 10^{10}$ & $1 \times 10^{10}$ & - & - & - \\
\hline
\end{tabular}

\begin{tabular}{cccccc}
\hline Item & Left Ring & Right Ring & Sun & Planet & Carrier \\
\hline Number of teeth & 57 & 57 & 23 & 17 & - \\
Angle of helix (deg.) & 25 & 25 & 25 & 25 & - \\
Normal pressure angle (deg.) & 20 & 20 & 20 & 20 & - \\
Mass (kg) & 450 & 450 & 750 & 525 & 5091 \\
Equivalent inertia J/r ${ }^{2}(\mathrm{~kg})$ & 546 & 546 & 663 & 420 & 5724 \\
Input torque (KN·m) & & & 100 & & \\
Input rotating speed $(\mathrm{rpm})$ & & & 100 & & \\
\hline
\end{tabular}

Table 2. HPGT stiffness parameters.

To investigate the impacts of planet-gear eccentricity $E_{\mathrm{p} 1}$ on the HPGT dynamic features, the planet-gear eccentric error is assumed to be $E_{\mathrm{p} 1}=100 \mu \mathrm{m}$, while the other manufacturing errors are not considered. The planet-gear eccentricity is defined to be the deviation between the realistic and theoretical rotational center as depicted in Figure 7 which shows a schematic of the planet-gear eccentricity. 


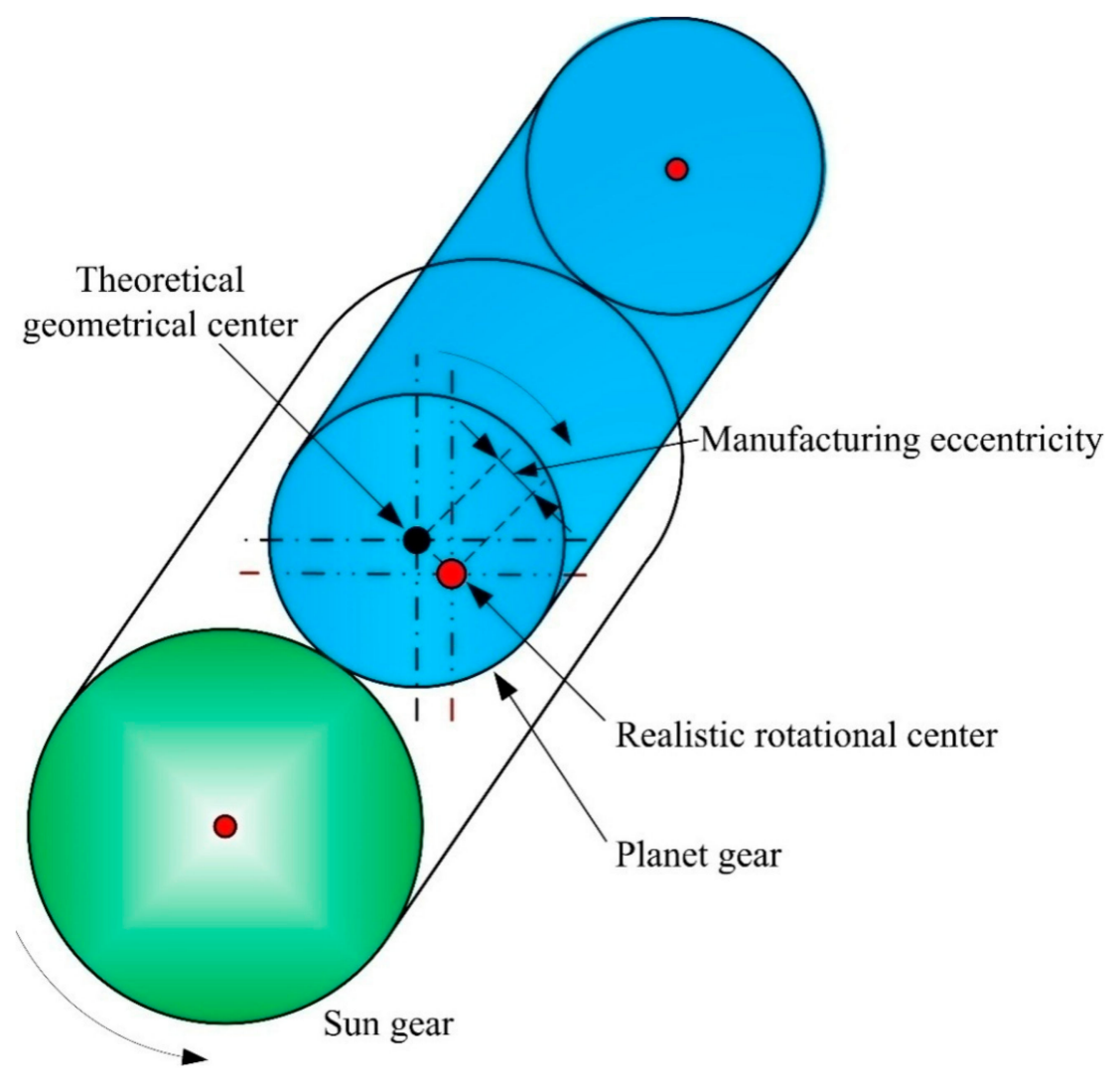

Figure 7. Definition of the planet-gear eccentricity.

\subsection{Dynamic Meshing Forces}

Figure 8 illustrates the time-domain responses of the dynamic meshing force on the right-side planet-sun gear pair, which is represented as $F_{s p 1}^{R}(t)\left(F_{s p 1}^{R}(t)=\Theta_{s p 1}^{R} \cdot k_{s p 1}^{R}\right.$, where $\Theta_{s p 1}^{R}$ and $k_{s p 1}^{R}$ are the same as those in Equations (5) and (18)), for two cases of with and without planet-gear eccentric error. For the sake of clarity, just one side of the dynamic meshing forces of a part of the time interval for the HPGT is demonstrated in Figure 8. It can be observed from Figure 8 that because the input torque of the system $T_{i n}=100 \mathrm{KN} \cdot \mathrm{m}$ is constant, the dynamic meshing forces of the right-side meshing pair possess no low-frequency components for both models with and without the planet-gear eccentric error excitations. The average values of the dynamic meshing forces for the models with and without the planet-gear eccentric error excitations are approximately $57 \mathrm{KN}$ as shown by the red dot-dash lines in Figure 8a,b. A comparison of Figure $8 \mathrm{a}, \mathrm{b}$ indicates that the meshing force fluctuation amplitude from the model with the planet-gear eccentric error excitation $E_{p 1}=100 \mu \mathrm{m}$ is obviously larger than that without error excitations. That is to say, the planet-gear eccentric error excitation increases the meshing force amplitude significantly in contrast to the model without manufacturing error excitations. The similar tendency is also able to be discovered for the meshing forces on one side of internal (planet-ring) meshing pair. In short, the planet-gear eccentric error excitation prominently increases the dynamic meshing force fluctuation amplitude for herringbone planetary gears. 
(a)

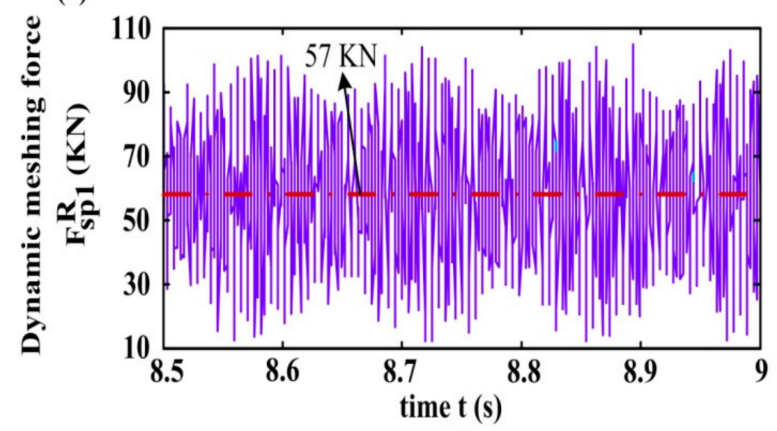

(b)

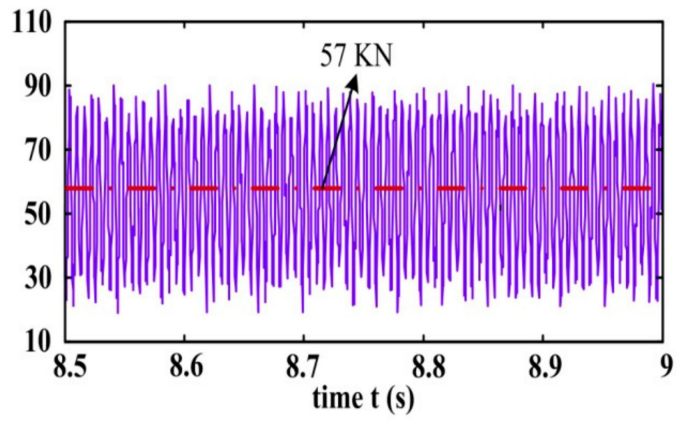

Figure 8. Variation of the dynamic meshing force on the right-side external meshing pair with gear mesh time, expressed as $F_{\mathrm{sp} 1}^{\mathrm{R}}$. (a) the model with the planet-gear eccentric error excitation $E_{\mathrm{p} 1}=100 \mu \mathrm{m}$, (b) the model without error excitations.

Figure 9 presents the dynamic meshing force $F_{s p 1}^{R}(t)$ frequency spectra on the right-side external (planet-sun) meshing pair, where (a) and (b) show the results for the model with and without the planet-gear eccentric error excitations, respectively, which are acquired using the signal processing method of fast Fourier transform (FFT) to transform the time domain response as shown in Figure 8 into the frequency domain. For the model with the planet eccentricity, it is found from Figure 9a that some main frequencies of $27.3 \mathrm{~Hz}, 133 \mathrm{~Hz}, 162 \mathrm{~Hz}, 213 \mathrm{~Hz}, 232 \mathrm{~Hz}, 507 \mathrm{~Hz}, 613 \mathrm{~Hz}, 1187 \mathrm{~Hz}$, and $1523 \mathrm{~Hz}$ appear in the right-side dynamic meshing force $F_{s p 1}^{R}(t)$ frequency spectra. The peak value of $F_{s p 1}^{R}(t)$ frequency spectra at the frequency of $0 \mathrm{~Hz}$ is maximum, and it is the direct current component of $F_{s p 1}^{R}(t)$. As is shown in Figure 9a, the dynamic meshing force $F_{s p 1}^{R}(t)$ amplitude at the frequency of $0 \mathrm{~Hz}$ is $57 \mathrm{KN}$, which is exactly the same as the average value of the dynamic meshing force $F_{s p 1}^{R}(t)$ in the time domain shown in Figure 8. In addition, at $162 \mathrm{~Hz}$ is associated with the 7th order natural frequency in HPGT, and the peak value of $F_{s p 1}^{R}(t)$ frequency spectra is the second highest. The $133 \mathrm{~Hz}$, $213 \mathrm{~Hz}, 232 \mathrm{~Hz}, 507 \mathrm{~Hz}, 613 \mathrm{~Hz}, 1187 \mathrm{~Hz}, 1523 \mathrm{~Hz}$, and $27.3 \mathrm{~Hz}$ are associated with the 5-, 8-, 9-, 14-, 16-, 22-, 26-th natural frequencies and the mesh frequency of the HPGT system, respectively. Therefore, it can be concluded that in the model with the planet eccentricity, as shown in Figure 9a, the dynamic meshing force $F_{s p 1}^{R}(t)$ frequency spectrum demonstrates the appearance of larger amplitudes at the meshing frequency and some natural frequencies of HPGT. The frequency spectrum characteristics of dynamic meshing force are in fairly good agreement with the results of modal analysis. Figure $9 \mathrm{~b}$ displays the $F_{s p 1}^{R}(t)$ frequency spectrum from the model without error excitations. By comparing Figure $9 a, b$, it is noted that the variation amplitudes of dynamic mesh forces with the planet eccentricity excitation are remarkably greater than those without error excitations. Thus, the manufacturing error excitations such as the planet eccentricity enhance the meshing force fluctuation.

(a)

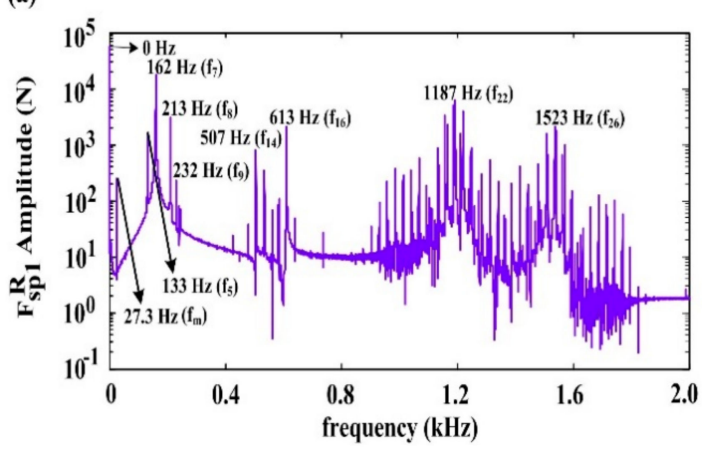

(b)

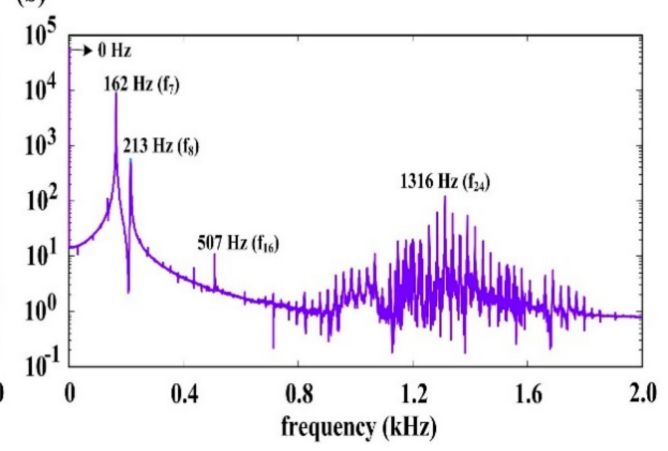

Figure 9. Frequency spectra of the dynamic meshing force $F_{\mathrm{sp} 1}^{\mathrm{R}}(t)$ at the right-side gear pair. (a) the model with the planet-gear eccentric error excitation $E_{\mathrm{p} 1}=100 \mu \mathrm{m},(\mathbf{b})$ the model without error excitations. 


\subsection{Dynamic Bearing Forces}

Figure 10 illustrates the variation of the bearing forces of some main components involving the carrier, sun and planet in the HPGT system with gear mesh time (denoted as $F_{c}, F_{s}$, and $F_{p 1}$, respectively). For the model with the planet-gear eccentric error excitation, as displayed in Figure 10a-c, it is observed that dynamic bearing forces for each component (carrier, sun and planet-gear) fluctuate prominently and periodically. The variation of the planet-gear dynamic bearing force is the most significant in each component of the system, and the variation of the sun gear bearing force is relatively smaller, owing to better flexible support of the sun gear. Figure $10 \mathrm{~d}-\mathrm{f}$ represent the dynamic bearing force from the model without manufacturing error excitations. A comparison of Figure $10 \mathrm{~d}-\mathrm{f}$ with Figure 10a-c shows the amplitudes of the dynamic bearing forces for each component in the presence of the planet eccentricity excitations are pronouncedly bigger than those in the absence of error excitations. In contrast to the results for the model in the absence of error excitations, the dynamic bearing forces of each component with the planet-gear eccentric error excitations have larger cyclical fluctuations; in particular, the variations of the planet-gear dynamic bearing forces are the most obvious in comparison with other components (carrier, sun gear), and the maximum amplitude of dynamic bearing forces of the planet-gear changes from $4.5 \times 10^{4} \mathrm{~N}$ without error excitation, as shown in Figure 10f, to $7.8 \times 10^{4} \mathrm{~N}$ with the planet-gear eccentric error excitation displayed in Figure $10 \mathrm{c}$, that of the carrier from $0.25 \times 10^{4} \mathrm{~N}$ without errors shown in Figure $10 \mathrm{~d}$ to $1.8 \times 10^{4} \mathrm{~N}$ with errors shown in Figure 10a, with more obvious changes, and that of the sun gear from $0.1 \times 10^{4} \mathrm{~N}$ without error excitation shown in Figure 10e to $0.6 \times 10^{4} \mathrm{~N}$ with error excitation shown in Figure 10b, also with more significant variations. By comparing Figure 10a-c with Figure $10 \mathrm{~d}-\mathrm{f}$, it is noted that manufacturing error excitations such as the planet-gear eccentric error enhance the dynamic bearing force fluctuation for each component in HPGT system, and the dynamic bearing force fluctuation for each component shows apparent periodicity.
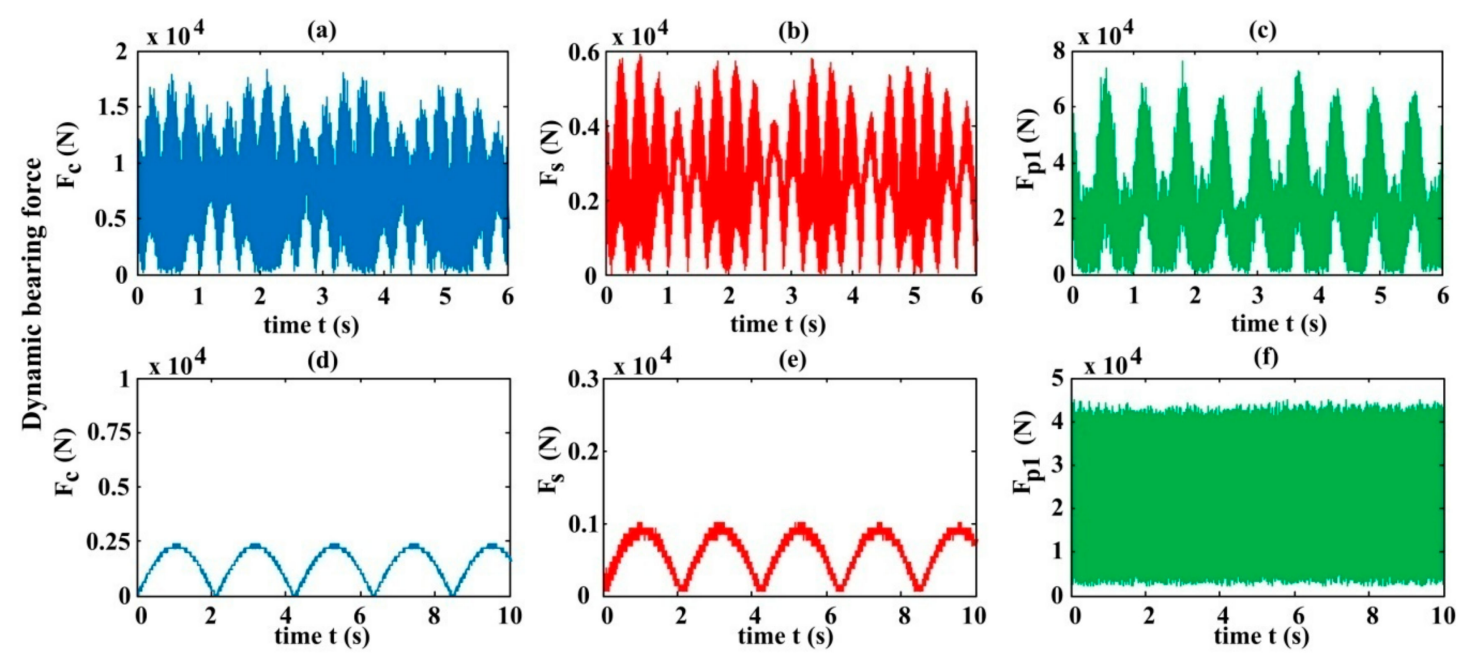

Figure 10. Variation of the dynamic bearing forces of main components $((\mathbf{a}, \mathbf{d})$ carrier, $(\mathbf{b}, \mathbf{e})$ sun, and $(\mathbf{c}, \mathbf{f})$ planet) with gear mesh time, which are represented as $F_{c}, F_{s}$, and $F_{p 1}$, respectively. (a-c) the model with the planet-gear eccentric error excitation $E_{\mathrm{p} 1}=100 \mu \mathrm{m}$; while $(\mathbf{d}-\mathbf{f})$ the model without error excitations.

\subsection{Vibration Accelerations of the Components}

Figure 11 illustrates the variations of the accelerations in $x-, y-, z-$, and $u$-directions for some main components of HPGT (i.e., the carrier, sun and planet) with gear mesh time (denoted as $\mathrm{a}_{\mathrm{ix}}, \mathrm{a}_{\mathrm{iy}}, \mathrm{a}_{\mathrm{iz}}$, $\mathrm{a}_{\mathrm{iu}}(\mathrm{i}=\mathrm{c}, \mathrm{s}, \mathrm{p} 1)$, respectively), which reflect the vibrations of main system components involving the carrier, sun, and planet in the corresponding directions, respectively, for the case of the planet eccentricity $E_{\mathrm{p} 1}=100 \mu \mathrm{m}$, while Figure 12 shows the results for the case of without error excitations. For the model with the planet-gear eccentric error excitation, the time-domain vibration accelerations 
at each degree of freedom of system components behave the fluctuation up and down around the horizontal zero axis; the component vibration accelerations in the $z$-direction (i.e., axial direction) are pronouncedly smaller than in the lateral directions (i.e., $x, y$-direction), induced by the symmetrical tooth structure of herringbone gear, making the axial forces of each component smaller. The carrier vibration accelerations in the horizontal, vertical, axial, and torsional directions are smaller than those in the corresponding directions of the sun and planet, possibly owing to the larger carrier inertia as given in Table 1 . The vibration accelerations in $x$-, and $y$-directions of the planet-gear are larger than those in the corresponding directions of other components such as the carrier and sun gear, particularly the vibration acceleration in the $y$-direction (i.e., tangential direction) of the planet-gear is the greatest, due to the larger force transmitting power in the planet tangential direction. In the vibration accelerations in the torsional direction of each component, the sun acceleration is greater, with the maximal amplitude of $300 \mathrm{~m} \cdot \mathrm{s}^{-1}$, and that of the planet-gear is also relatively large, with great amplitude of $275 \mathrm{~m} \cdot \mathrm{s}^{-1}$.

(a)

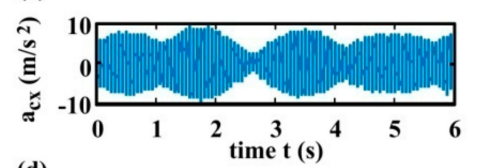

(d)
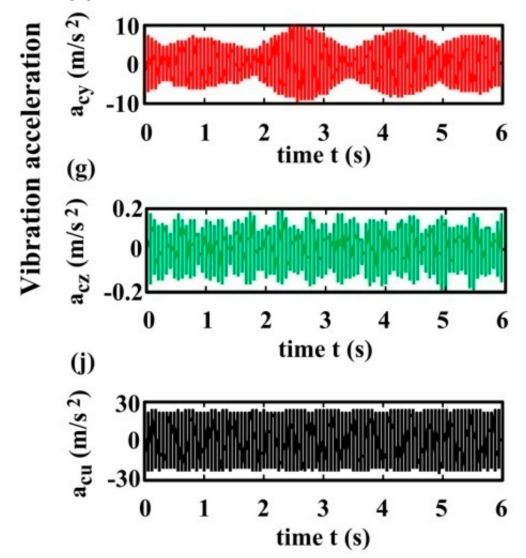

(b)

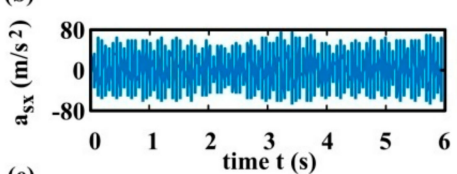

(e)

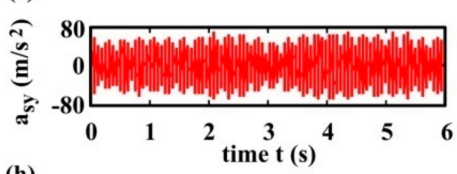

(h)
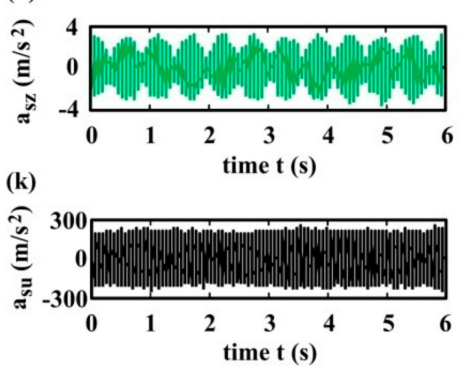

(c)

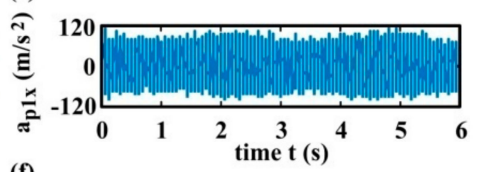

(f)

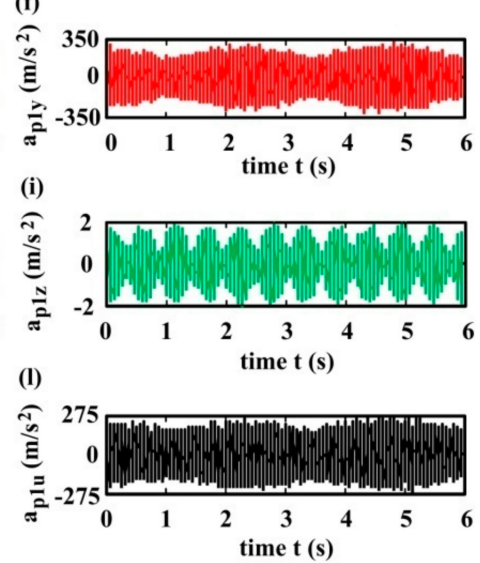

Figure 11. Variations of the vibration accelerations of the main components from the model in the presence of the planet-gear eccentric error excitation $E_{\mathrm{p} 1}=100 \mu \mathrm{m}$ with gear mesh time. $(\mathbf{a}, \mathbf{d}, \mathbf{g}, \mathbf{j})$ the carrier accelerations in $x_{-}, y_{-}, z_{-}$, and $u$-directions, represented as $\mathrm{a}_{\mathrm{cx}}, \mathrm{a}_{\mathrm{cy}}, \mathrm{a}_{\mathrm{cz}}$, and $\mathrm{a}_{\mathrm{cu}}$, respectively; $(\mathbf{b}, \mathbf{e}, \mathbf{h}, \mathbf{k})$ the sun accelerations in $x-, y-, z-$, and $u$-directions, represented as $\mathrm{a}_{\mathrm{sx}}, \mathrm{a}_{\mathrm{sy}}, \mathrm{a}_{\mathrm{sz}}$, and $\mathrm{a}_{\mathrm{su}}$, respectively; $(\mathbf{c}, \mathbf{f}, \mathbf{i}, \mathbf{l})$ the planet accelerations in $x-, y-, z-$, and $u$-directions, represented as $\mathrm{a}_{\mathrm{p} 1 \mathrm{x}}, \mathrm{a}_{\mathrm{p} 1 \mathrm{y}}, \mathrm{a}_{\mathrm{p} 1 \mathrm{z}}$, and $\mathrm{a}_{\mathrm{p} 1 \mathrm{u}}$, respectively.

Figure 12 exhibits the variations of the accelerations for some main components of HPGT (i.e., the carrier, sun and planet) with gear mesh time (denoted as $\mathrm{a}_{\mathrm{ix}}, \mathrm{a}_{\mathrm{iy}}, \mathrm{a}_{\mathrm{iz}}, \mathrm{a}_{\mathrm{iu}}(\mathrm{i}=\mathrm{c}, \mathrm{s}, \mathrm{p} 1$ ), respectively), which reflect the vibrations of main system components containing the carrier, sun, and planet in the corresponding directions, respectively, for the case of the absence of manufacturing error excitations. A comparison of Figure 11a-c with Figure 12a-c indicates that in HPGT system, the vibration acceleration amplitudes in the $x$-direction of each component for the model without errors become evidently smaller than those for the model with the planet-gear eccentric error excitation, particularly the amplitude variation of vibration accelerations in the $x$-direction of the planet-gear is the most distinct in the two models with and without error excitations, on account of the planet eccentricity excitations. In the meantime, it is also seen that the vibration acceleration amplitudes in the $y$-direction of each member in the absence of error excitations displayed in Figure 12 are also noticeably smaller than those in the presence of the planet eccentricity excitation displayed in Figure 11, probably because of the planet-gear eccentricity excitation. The same tendency is also found for the vibration acceleration 
amplitudes in the $u$-direction (i.e., torsional direction) of each component. From Figure $11 \mathrm{~g}, \mathrm{~h}, \mathrm{j}$ and Figure $12 \mathrm{~g}, \mathrm{~h}, \mathrm{j}$, it can be observed that for the model with the planet-gear eccentric error excitation, the vibration accelerations in the $z$-direction of the herringbone sun, herringbone planet, and carrier are small but nonzero; while for the model in the absence of error excitations, the $z$-direction vibration accelerations of the herringbone sun, planet, and carrier disappear, similar to the spur planetary gears. This means that manufacturing error excitations are the vibration source of the axial direction and directly impact the axial vibration of each member in the HPGT system.
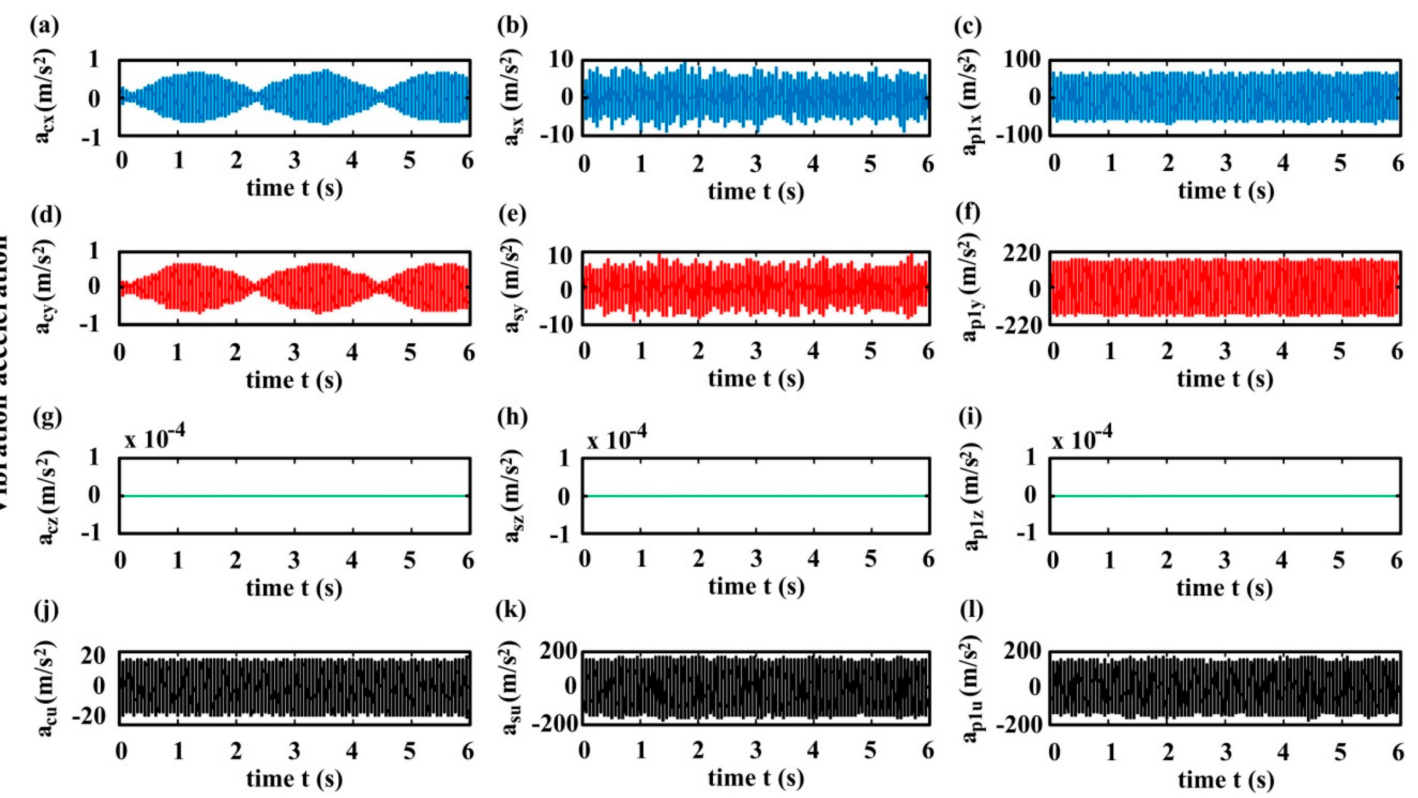

Figure 12. Variations of the vibration accelerations of the main members from the model in the absence of error excitations with gear mesh time. $(\mathbf{a}, \mathbf{d}, \mathbf{g}, \mathbf{j})$ the carrier accelerations in $x_{-}, y_{-}, z_{-}$, and $u$-directions, expressed as $\mathrm{a}_{\mathrm{cx}}, \mathrm{a}_{\mathrm{cy}}, \mathrm{a}_{\mathrm{cz}}$, and $\mathrm{a}_{\mathrm{cu}}$, respectively; (b,e,h, $\left.\mathbf{k}\right)$ the sun accelerations in $x-, y-, z_{-}$, and $u$-directions, expressed as $\mathrm{a}_{\mathrm{sx}}, \mathrm{a}_{\mathrm{sy}}, \mathrm{a}_{\mathrm{sz}}$, and $\mathrm{a}_{\mathrm{su}}$, respectively; $(\mathbf{c}, \mathbf{f}, \mathbf{i}, \mathbf{l})$ the planet accelerations in $x$-, $y-, z-$, and $u$-directions, expressed as $\mathrm{a}_{\mathrm{p} 1 \mathrm{x}}, \mathrm{a}_{\mathrm{p} 1 \mathrm{y}}, \mathrm{a}_{\mathrm{p} 1 \mathrm{z}}$, and $\mathrm{a}_{\mathrm{p} 1 \mathrm{u}}$, respectively.

Through comparing the results obtained from the model in the presence of the planet eccentricity shown in Figure 11 and those in the absence of the error shown in Figure 12, it is seen that manufacturing error excitations such as the planet eccentricity $E_{p 1}$ enhance the vibration acceleration responses in each DOF direction of each component in HPGT system, and the vibrations in the axial direction of HPGT are smaller and even vanishes similar to PGT with spur teeth when the planet-gear eccentricity is sufficiently small. In short, manufacturing error excitations such as the planet eccentricity increase the vibration acceleration responses of the herringbone planetary gears.

\section{Conclusions}

In this study, by considering the HPGT actual structure characteristics, manufacturing eccentric errors of components (i.e., each gear, and carrier), tooth profile errors of gears, gear tooth time-varying meshing stiffness and bearing deflections, different from the two-dimensional model, a novel and generalized three-dimensional lumped-parameter dynamic model of herringbone planetary gears has been given for studying the dynamic feature of the HPGT system in the presence of arbitrary number of planets and different types of manufacturing errors. The effects of manufacturing errors such as the planet eccentricity on the HPGT dynamic features were investigated. The main conclusions are given below.

(1) Manufacturing errors such as the planet eccentricity prominently affect the HPGT dynamic features, and the manufacturing error excitations significantly increase the fluctuations of the 
dynamic meshing forces, dynamic bearing forces, and vibrations of components of herringbone planetary gears.

(2) The fluctuations of the dynamic meshing forces and dynamic bearing forces for the model in the existence of the planet eccentricity excitation are evidently greater than those in the absence of error excitations. The amplitudes of vibration accelerations in each DOF direction of HPGT members for the model in the presence of the planet eccentricity excitation are also significantly larger than those in the absence of error excitations.

(3) Manufacturing error excitations such as the planet eccentricity distinctly impact the axial vibrations of the carrier, sun, and planet of HPGT. Manufacturing error excitations are the axial vibration source in the HPGT system. For the model in the absence of error excitations, the axial forces and vibrations of the HPGT disappear, similar to spur PGT.

This investigation provides the new effective idea and methodology for the prediction and analysis of the dynamic feature of complex herringbone planetary gear systems with other type of error faults, and also offers the theoretical foundation for the error fault diagnosis and dynamic optimization of herringbone planetary gears in the next step. Our ongoing investigation will focus on the studies of the effects of system stiffness on herringbone planetary gear dynamic response.

Author Contributions: F.R. presented the HPGT system dynamic model, analyzed the results, and wrote this paper; A.L. analyzed some simulation results and reviewed the manuscript; G.S. modified the first draft of the manuscript and guided the contribution; X.W. revised the manuscript and gave some helpful and valuable suggestions; N.W. analyzed some simulation results. All authors have read and agreed to the published version of the manuscript.

Funding: This research was funded by the Science and Technology Research Project of Henan Province (Grant Nos. 202102210085, 172102210056), the Open Funding of Henan Key Laboratory of Intelligent Manufacturing of Mechanical Equipment (Grant No. IM201912), and the Doctoral Science Research Foundation of Zhengzhou University of Light Industry (Grant No. 2015BSJJ030).

Acknowledgments: The authors would like to express their gratitude to A/ Jinchen Ji in the University of Technology Sydney in Australia for helping modify the manuscript, especially polishing the language, and they are also very grateful to the editors and reviewers for their valuable comments and suggestions.

Conflicts of Interest: The authors declare no conflict of interest.

\section{Abbreviations}

\section{Nomenclature}

$e$

$E_{j}$

$E_{\text {spi }}$

$\mathrm{I}_{j}$

$\mathrm{F}(\mathrm{t})$

G

$\mathrm{k}_{\text {spi }}^{\mathrm{R}}(\mathrm{t})$

$\mathrm{k}_{\text {spi }}^{\mathrm{L}}(\mathrm{t})$

$\mathrm{k}_{\text {rlpi }}^{\mathrm{R}}(\mathrm{t})$

$\mathrm{k}_{\mathrm{r} 2 \mathrm{pi}}^{\mathrm{L}}(\mathrm{t})$

$\mathrm{k}_{j}$

$\mathrm{k}_{\mathrm{jt}}$

$\mathrm{K}_{\mathrm{m}}, \mathrm{K}_{\mathrm{b}}$

$\mathrm{K}_{\omega}$

$m_{j}$

$\mathrm{M}$

N

$r_{j}$

$r_{c}$ static transmission error

manufacturing eccentric error of the component $(j=s, r 1, r 2, \mathrm{c}, \mathrm{p} 1, \ldots, \mathrm{pN})$

tooth profile error in the $i$ th sun-planet mesh $(i=1,2, \ldots, N)$

moment of inertial of the component $j(j=s, r 1, r 2, \mathrm{c}, \mathrm{p} 1, \ldots, \mathrm{pN})$

exciting force induced by the transmission error and time-varying mesh stiffness

gyroscopic matrix due to the rotation of the carrier

time-varying mesh stiffness of the right-side $i$ th sun-planet mesh $(i=1,2, \ldots, N)$

time-varying mesh stiffness of the left-side $i$ th sun-planet mesh $(i=1,2, \ldots, N)$

time-varying mesh stiffness of the right-side $i$ th ring-planet mesh $(i=1,2, \ldots, N)$

time-varying mesh stiffness of the left-side $i$ th ring-planet mesh $(i=1,2, \ldots, N)$

bearing supporting stiffness of the component $j(j=s, r 1, r 2, \mathrm{c}, \mathrm{p} 1, \ldots, \mathrm{pN})$

tangential support stiffness of the component $j(j=s, r 1, r 2, \mathrm{c})$

stiffness matrix related to gear mesh and bearing supporting

stiffness matrix related to the centrifugal effect of planets

mass of the component $j(j=s, r 1, r 2, \mathrm{c}, \mathrm{p})$

mass matrix of the whole system

number of planets

base circle radius of the component $j(j=s, r 1, r 2, \mathrm{p})$

radius of the circle passing through the planet centers 


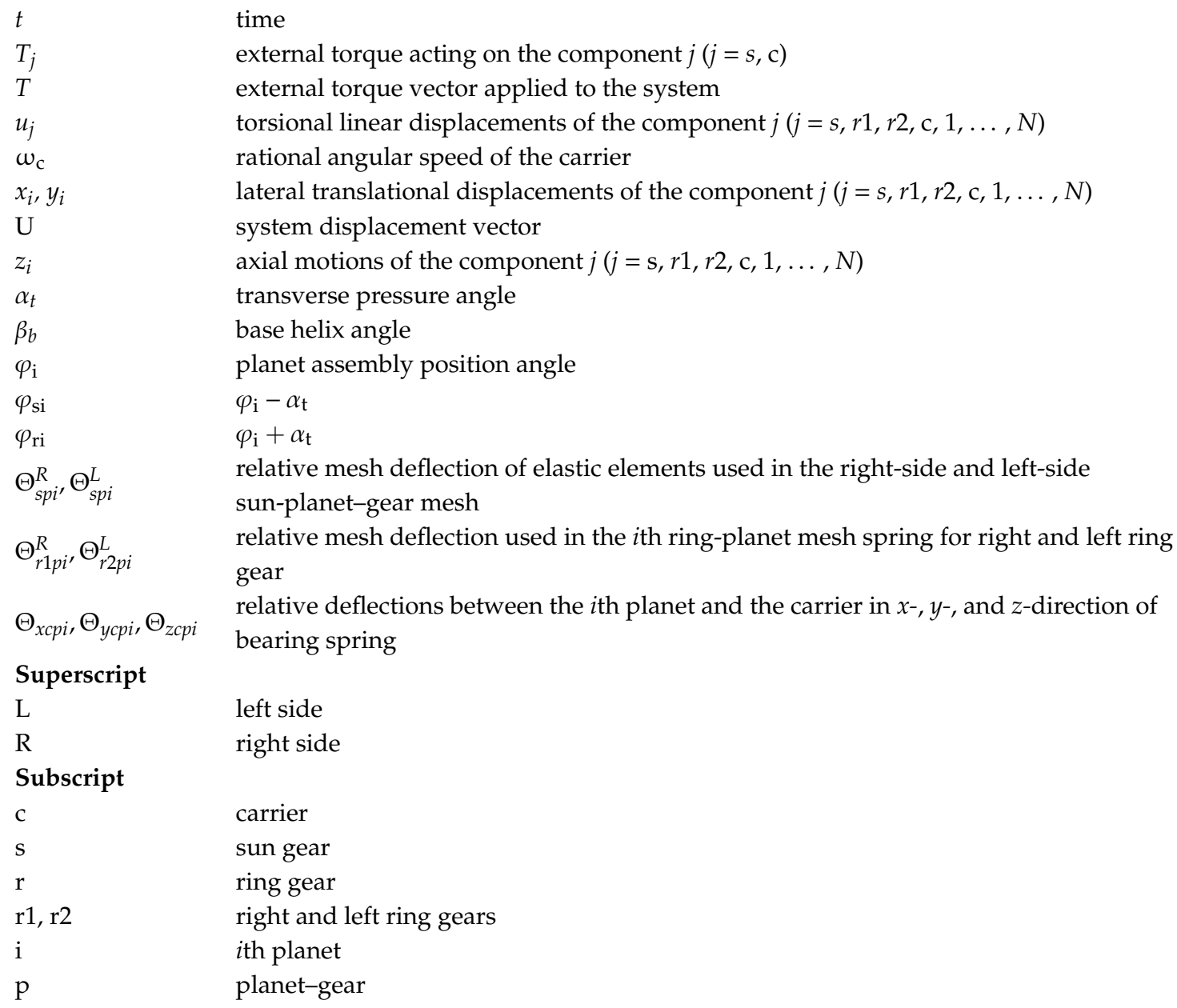

\section{References}

1. Lin, J.; Parker, R.G. Planetary gear parametric instability caused by mesh stiffness variation. J. Sound Vib. 2002, 249, 129-145. [CrossRef]

2. Lin, J.; Parker, R.G. Analytical characterization of the unique properties of planetary gear free vibration. J. Vib. Acoust. 1999, 121, 316-321. [CrossRef]

3. Guo, Y.; Parker, R.G. Dynamic modeling and analysis of a spur planetary gear involving tooth wedging and bearing clearance nonlinearity. Eur. J. Mech. A-solid. 2010, 29, 1022-1033. [CrossRef]

4. Zhao, M.; Ji, J. Nonlinear torsional vibrations of a wind turbine gearbox. Appl. Math. Model. 2015, 39, 4928-4950. [CrossRef]

5. Kahraman, A. Planetary gear train dynamics. J. Mech. Des. 1994, 116, 713-720. [CrossRef]

6. Tatar, A.; Schwingshackl, C.; Friswell, M. Dynamic behaviour of three-dimensional planetary geared rotor systems. Mech. Mach. Theory 2019, 134, 39-56. [CrossRef]

7. $\mathrm{Bu}, \mathrm{Z}$.; Liu, G.; Wu, L. Modal analyses of herringbone planetary gear train with journal bearings. Mech. Mach. Theory 2012, 54, 99-115. [CrossRef]

8. Sondkar, P.; Kahraman, A. A dynamic model of a double helical planetary gear set. Mech. Mach. Theory 2013, 70, 157-174. [CrossRef]

9. Chaari, F.; Fakhfakh, T.; Hbaieb, R.; Louati, J.; Hadder, M. Influence of manufacturing errors on the dynamic behavior of planetary gears. Int. J. Adv. Manuf. Technol. 2006, 27, 738-746. [CrossRef]

10. Xu, X.; Liu, H.; Ma, F.; Li, G. Load sharing research of planetary gear transmission system of wind turbine gearbox with flexible pins. J. Mech. Eng. 2014, 50, 43-49. [CrossRef]

11. Ren, F.; Qin, D.; Lim, T.; Lyu, S. Study on dynamic characteristics and load sharing of a herringbone planetary gear with manufacturing errors. Int. J. Precis. Eng. Manuf. 2014, 15, 1925-1934. [CrossRef] 
12. Ren, F.; Luo, G.; Shi, G.; Wu, X.; Wang, N. Influence of manufacturing errors on dynamic floating characteristics for herringbone planetary gears. Nonlinear Dyn. 2018, 93, 361-372. [CrossRef]

13. Ren, F.; Qin, D.; Wu, X. Load sharing performances of herringbone planetary gears considering manufacturing errors. J. Cent. South Univ. (Sci. Technol.) 2016, 47, 474-481.

14. Qin, D.; Ren, F.; Wu, X. Effect of sun gear manufacturing eccentric errors on dynamic performances of herringbone planetary gear train. J. Northeast Univ. (Nat. Sci. Ed.) 2015, 36, 709-714.

15. Zhu, Z.; Zhu, R.; Bao, H.; Jin, G. Impact of run-out and meshing-frequency errors on dynamic load sharing for encased differential herringbone train. J. Aerosp. Eng. 2011, 26, 2601-2609.

16. Apuzzo, A.; Barretta, R.; Faghidian, S.A.; Luciano, R.; De Sciarra, F.M. Free vibrations of elastic beams by modified nonlocal strain gradient theory. Int. J. Eng. Sci. 2018, 133, 99-108. [CrossRef]

17. Hu, J.; Mei, B.; Peng, H.; Jiang, X. Optimization design and analysis for a single motor hybrid powertrain configuration with dual planetary gears. Appl. Sci. 2019, 9, 707. [CrossRef]

18. Zhang, R.; Xi, G.; Gu, F.; Wang, T.; Ball, A. Gear wear process monitoring using a sideband estimator based on modulation signal bispectrum. Appl. Sci. 2017, 7, 274. [CrossRef]

19. Li, X.; Li, J.; Qu, Y.; He, D. Gear pitting fault diagnosis using integrated CNN and GRU network with both vibration and acoustic emission signals. Appl. Sci. 2019, 9, 768. [CrossRef]

20. Lou, Z.; Xue, P.; Zheng, Y.; Fan, K. An analysis of angular indexing error of a gear measuring machine. Appl. Sci. 2018, 8, 169. [CrossRef]

21. Faghidian, S.A.; Goudar, D.; Farrahi, G.H.; Smith, D.J. Measurement, analysis and reconstruction of residual stresses. J. Strain Anal. Eng. 2012, 47, 254-264. [CrossRef]

22. Maatar, M.; Velex, P. An analytical expression for the time-varying contact length in perfect cylindrical gears: Some possible applications in gear dynamics. J. Mech. Des. 1996, 118, 586-589. [CrossRef]

(C) 2020 by the authors. Licensee MDPI, Basel, Switzerland. This article is an open access article distributed under the terms and conditions of the Creative Commons Attribution (CC BY) license (http://creativecommons.org/licenses/by/4.0/). 